\title{
Nivalenol-Type Populations of Fusarium graminearum and F. asiaticum Are Prevalent on Wheat in Southern Louisiana
}

\author{
Liane Rosewich Gale, Stephen A. Harrison, Todd J. Ward, Kerry O’Donnell, \\ Eugene A. Milus, Samuel W. Gale, and H. Corby Kistler
}

First and seventh authors: Department of Plant Pathology, University of Minnesota, St. Paul; second author: Department of Agronomy, Louisiana State University, Baton Rouge; third and fourth authors: United States Department of Agriculture-Agricultural Research Service (USDA-ARS), National Center for Agricultural Utilization Research Laboratory, Peoria, IL; fifth author: Department of Plant Pathology, University of Arkansas, Fayetteville; and sixth and seventh authors: USDA-ARS, Cereal Disease Laboratory, St. Paul, MN. Accepted for publication 12 August 2010.

\begin{abstract}
Gale, L. R., Harrison, S. A, Ward, T. J., O’Donnell, K., Milus, E. A., Gale, S. W., and Kistler, H. C. 2011. Nivalenol-type populations of Fusarium graminearum and $F$. asiaticum are prevalent on wheat in southern Louisiana. Phytopathology 101:124-134.

U.S. populations of the Fusarium graminearum clade cause head blight on wheat and barley and usually contaminate grain with the trichothecene mycotoxin deoxynivalenol (DON). Recently, however, individual nivalenol (NIV)-type isolates from the United States were described that belonged to either the newly described species $F$. gerlachii or the genetically distinct Gulf Coast population of $F$. graminearum sensu stricto (s.s.). Here, we describe the discovery of NIV-type $F$. graminearum s.s. populations that were found in high proportion (79\%) among isolates from small-grain-growing regions of Louisiana. We genotyped 237 isolates from Louisiana with newly developed polymerase chain reaction (PCR) restriction fragment length polymorphism markers and multiplex PCR primers that distinguish among the three trichothecene types: the two DON types (15ADON and 3ADON) and NIV. These

predominantly from the Midwest. Using Bayesian-model-based clustering, we discovered a southern Louisiana population of $F$. graminearum s.s. that was genetically distinct from the previously recognized pathogen population in the Midwest (MW15ADON population). Population membership was correlated with trichothecene type. Most isolates from the southern Louisiana population were of the NIV type, while the majority of the isolates from the Midwest were of the 15ADON type. A smaller proportion of isolates from Louisiana belonged to the previously described Gulf Coast population that was mostly of the 3ADON type. The NIV type was also identified in collections from Arkansas (12\%), North Carolina $(40 \%)$, and Missouri $(2 \%)$, with the collections from Arkansas and North Carolina being small and unrepresentative. F. asiaticum was detected from the two southern Louisiana parishes Acadia and Alexandria. All identified $41 \mathrm{~F}$. asiaticum isolates were of the NIV type. Greenhouse tests indicated that U.S. NIV types accumulated four times less trichothecene toxin than DON types on inoculated wheat. This is the first report of NIV-type populations of $F$. graminearum $s . s$. and $F$. asiaticum in the United States.
\end{abstract} isolates were compared with 297 isolates from 11 other U.S. states,
Head blight $(\mathrm{HB})$ or scab is a devastating disease of wheat and barley (39) and is notorious for causing massive economic losses in epidemic years, in which yield can be reduced by 30 to $70 \%$ (1). Direct economic losses due to HB epidemics are incurred by yield reduction, field abandonment, and quality discounts due to decreased test weight. Contamination with mycotoxins may render whole lots unfit for animal or human consumption. These losses were estimated at close to $\$ 3$ billion in the United States during the 1990s (49), with many Midwestern states suffering major epidemics during that time (26). Indirect economic losses for the regional economy and negative social impacts associated with HB epidemics $(26,31,49)$ further amplify its destructive power. Although the Upper Midwest has been the hardest hit within the United States $(31,49)$, other regions are not immune from epidemics. For example, a severe HB outbreak in 2003 caused unprecedented losses in the southeastern United States (5).

Worldwide, members of the Fusarium graminearum species complex are the main causal agents of HB. Rigorous application

Corresponding author: L. R. Gale; E-mail address: lianeg@umn.edu

Any opinions, findings, conclusions, or recommendations expressed in this publication are those of the authors and do not necessarily reflect the view of the USDA.

doi:10.1094/PHYTO-03-10-0067

This article is in the public domain and not copyrightable. It may be freely reprinted with customary crediting of the source. The American Phytopathological Society, 2011. of genealogical concordance phylogenetic species recognition (45), based on phylogenetic analysis of $16 \mathrm{~kb}$ of unique DNA sequence data consisting of portions of seven independent loci, identified 14 cryptic species within the $F$. graminearum clade $(32-34,41,47,52)$. Although some interfertility has been demonstrated among some of the $F$. graminearum clade species in the laboratory (3), their genealogical exclusivity strongly indicates that little or no gene flow has occurred among the various species over an extended period of time spanning multiple speciation events in nature. Moreover, field studies where two or more of the $F$. graminearum clade species are sympatric indicate that interspecific hybridization has had no impact on species boundaries $(21,43)$. In addition, evidence of ecological specialization within the $F$. graminearum clade $(21,52)$ further supports their status as distinct species. The species designation $F$. graminearum will therefore be sensu stricto, and other $F$. graminearum clade species designations will be used as described $(34,41)$

An assessment of the $F$. graminearum clade diversity in samples collected from 1999 to 2000 (15) confirmed a previous finding by Zeller et al. (54) that $F$. graminearum is the predominant HB species in the United States. Among 713 F. graminearum clade isolates from nine Midwestern states, all but 1 was identified as F. graminearum (15). The one exception was strain 00-551 (=NRRL 36905), which was subsequently designated as the type for $F$. gerlachii, a newly described species in the $F$. graminearum clade (41) that is present at very low frequency in Minnesota, North Dakota, and Wisconsin (L. R. Gale, unpublished data). 
The current study is based on initial results from pathogen population surveys in the southern and Midwestern United States that were conducted annually from 2001 to 2007, analogous to the surveys of 1999 to 2000 (15). When determining trichothecene type using a multiplex polymerase chain reaction (PCR) assay (41), field collections from Louisiana segregated for all three types - the two deoxynivalenol (DON) types (15ADON and 3ADON) and nivalenol (NIV)—with the majority being classified as the NIV type. This was surprising because cereals in the United States have not been found to be contaminated with NIV (29), although individual isolates of the $F$. graminearum clade with the NIV type have been described previously $(15,41)$. In addition, $F$. cerealis that is occasionally found in U.S. grain (L. R. Gale, unpublished) is a known NIV producer.

Trichothecene toxins produced by Fusarium spp. have the potential to elicit severe toxicoses in humans and farm animals (7). Various members of the genus Fusarium produce many of these tricyclic sesquiterpenes, with several of them produced in sufficient quantities in food or feed to be of a general health concern. DON and NIV contamination of cereal grain in the major cereal-producing regions of the world, and especially North America and Europe, has been due in large part to infection of members of the $F$. graminearum clade (50). Although some studies have determined that DON and NIV appear to have similar cytotoxicity (9), others observed higher toxicity for NIV (28). Due to an equal or potentially higher toxicity of NIV compared with DON, it is imperative to determine the geographic distribution and proportion of NIV producers in HB pathogen populations in the United States and to assess their toxigenic potential on plant host species. This is especially important because the United States Department of Agriculture (USDA) agency Grain Inspection, Packers and Stockyards Administration (GIPSA) lists performance-verified rapid test kits for analysis of mycotoxins for certification of DON but not for NIV, for which kits are currently not available. Consequently, levels of NIV are currently not routinely measured in U.S. grain and, unlike for DON, no Food and Drug Administration advisory guidelines have been provided for NIV.

The objectives of the current study were to (i) establish a representative collection of $F$. graminearum clade HB isolates from Louisiana from both commercial fields and nurseries, (ii) ascertain the trichothecene type for these isolates, (iii) determine the toxigenic potential of NIV producers from the United States and compare them with DON producers, and (iv) develop and utilize polymorphic molecular markers to determine the genetic relationship between NIV- and DON-producing isolates of the $F$. graminearum clade from the southern and Midwestern United States.

\section{MATERIALS AND METHODS}

Fungal collections and species identification. Many isolates were from plant material gathered during the course of wheat rust surveys that are conducted annually by personnel of the USDA Agricultural Research Service (ARS), Cereal Disease Lab, St. Paul, MN as described previously (15); other sources are listed in Table 1. Most isolates were sampled between 2001 and 2007. In total, 280 isolates from Louisiana belonging to the F. graminearum clade were established and examined in this study, whereby the majority originated from the parishes of Acadia $(n=$ 224), Jefferson Davis $(n=22)$, and Rapides $(n=20)$. The collection from Louisiana was compared with 37 isolates from five southern states (Alabama, Arkansas, North Carolina, Mississippi, and Texas) and 324 isolates from six Midwestern states (Illinois, Indiana, Kansas, Missouri, Nebraska, and Ohio) (Fig. 1). Ten isolates from Midwestern states that previously could not be placed into a specific population (15) were included and reanalyzed here. Species identification was done initially by visual assessment of conidial characteristics during single-sporing using an Olympus dissecting SZX12 microscope (Olympus America, Melville, NY). Additional species identification of a subset of 154 isolates from Louisiana was obtained by multilocus genotyping (MLGT) using allele-specific primer extension with 41 probes, which are specific for species of the $F$. graminearum clade or closely related species within the $\mathrm{B}$ trichothecene toxin-producing clade (48). Primer extension products in the MLGT assay were hybridized to a suspension microsphere array and were captured by complementary antitags attached to microspheres, which possess a unique spectral address. Microsphere complexes were detected by a Luminex 100 flow cytometer and scored by fluorescence intensity and spectrum.

TABLE 1. Origin of U.S. isolates of Fusarium graminearum analyzed in this study

\begin{tabular}{|c|c|c|c|c|}
\hline State & $\begin{array}{c}\text { No. of } \\
\text { counties }\end{array}$ & $\begin{array}{c}\text { No. of } \\
\text { isolates }^{\mathrm{w}}\end{array}$ & Collection years & County or parish \\
\hline Alabama & 2 & 2 & 03,05 & Autauga, Baldwin \\
\hline Arkansas $^{\mathrm{x}}$ & $\ldots$ & 26 & $1990 \mathrm{~s}$ & Unknown \\
\hline Illinois & 4 & 40 & $02,03,04,05,06,07$ & Jefferson, Lawrence, St. Clair, Washington \\
\hline Indiana & 10 & 76 & $01,02,03,04,06,07$ & Allen, Clinton, Delaware, Knox, La Porte, Montgomery, Noble, Randolph, Tippecanoe, Tipton \\
\hline Kansas & 2 & 21 & 04,07 & Allen, Republic, unknown \\
\hline Louisiana $^{\mathrm{y}}$ & 7 & 237 & $02,03,05,06,07$ & Acadia, Calcasieu, East Baton Rouge, Franklin, Jefferson Davis, Pointe Coupee, Rapides \\
\hline Missouri & 5 & 50 & $01,02,03,04,06,07$ & Knox, Lincoln, Marion, Monroe, Pike \\
\hline Mississippi & 1 & 1 & 02 & Hinds \\
\hline North Carolina ${ }^{\mathrm{z}}$ & 2 & 5 & 1996 & Ashe, Wayne \\
\hline Nebraska & 5 & 22 & 03,07 & Fillmore, Harlan, Jefferson, Lincoln, Thayer \\
\hline Ohio & 6 & 40 & $02,04,06$ & Darke, Defiance, Mercer, Putnam, Van Wert, Wood \\
\hline Texas & 1 & 3 & 07 & Brazos \\
\hline Others & Various & 11 & 1999,2000 & $\begin{array}{l}\text { Ten Midwestern isolates of } F \text {. graminearum that in previous analyses (15) could not be placed } \\
\text { into a specific population; plus } \mathrm{PH}-1 \text {, the sequenced and standard strain }(6)\end{array}$ \\
\hline Total & 45 & 534 & $\ldots$ & $\ldots$ \\
\hline
\end{tabular}

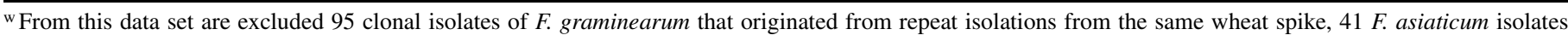
(from parishes Acadia and Alexandria, LA) and isolates 07-73 and 07-100 (both from Jefferson Davis Parish, LA) that displayed unusual genotypes, and 7 other isolates that were eventually determined to be non-graminearum.

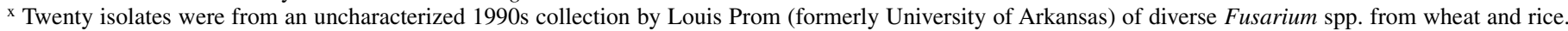
Isolates identified as F. graminearum were all from wheat hosts. An additional six isolates were collected from Arkansas in 1990 and have been routinely used for field inoculations in the state.

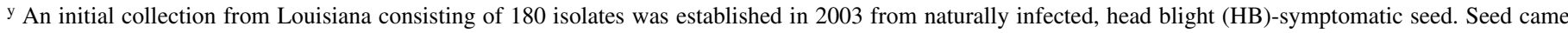
from wheat nurseries grown at the Rice Research Station of the AgCenter of Louisiana State University located near Crowley in Acadia Parish in middle-south Louisiana. In addition, Cereal Disease Lab personnel and collaborators from Louisiana collected HB-symptomatic wheat spikes from nurseries and commercial fields in 2002, 2003, 2005, and 2007 from a total of seven parishes in Louisiana.

${ }^{\mathrm{z}}$ Five isolates from North Carolina were from a previous study (46). 
Culturing and DNA extractions. Establishment of pure cultures from a single symptomatic seed, including their singlesporing and long-term storage, has been described previously (14). Fungal tissue for DNA extraction was grown in $3 \mathrm{ml}$ of complete medium (4) amended with chloramphenicol at $50 \mathrm{ppm}$ in 24-well polypropylene uniplates (Whatman, Piscataway, NJ). Cultures were grown at room temperature for 4 to 5 days on a rotary shaker at $150 \mathrm{rpm}$. Tissue was harvested with forceps, pelleted in 2-ml microfuge tubes, and rinsed once with $0.5 \mathrm{ml}$ of sterile water. Mycelium was stored at $-20^{\circ} \mathrm{C}$ before lyophilization (Labconco, Kansas City, MO) and DNA extraction. A small amount of 0.5 -mm glass beads was added to the freeze-dried tissue, and the tissue was homogenized in a Mini-Bead-Beater-8 (BioSpec Products, Bartlesville, OK) for 15 s. Using an Eppendorf Repeater Plus pipettor (Eppendorf, Mississauga, Ontario, Canada), $0.8 \mathrm{ml}$ of a cetyltrimethylammonium bromide-based DNA extraction buffer (20) was added to each tube, and the tubes were incubated in a $65^{\circ} \mathrm{C}$ water bath for $60 \mathrm{~min}$, while being agitated every $15 \mathrm{~min}$. After a short cooling-down period, $750 \mu \mathrm{l}$ of chloroform:isoamyl (24:1, vol/vol) was added, and the tubes were shaken and centrifuged at $10,500 \times g$ for $15 \mathrm{~min}$. Then, $\approx 600 \mu \mathrm{l}$ of the supernatant was transferred to labeled microfuge tubes that contained $700 \mu \mathrm{l}$ of isopropanol and $7.5 \mathrm{M}$ ammonium acetate $(4: 1 ; \mathrm{vol} / \mathrm{vol})$. The DNA was allowed to precipitate for $10 \mathrm{~min}$ at room temperature before being pelleted at maximum speed for $10 \mathrm{~min}$ in a microfuge. The DNA pellet was washed with $100 \mu \mathrm{l}$ of $70 \%$ ethanol and allowed to air dry for $\approx 15 \mathrm{~min}$ (open-capped, inverted tubes) before $50 \mu \mathrm{l}$ of Tris-EDTA buffer ( $\mathrm{pH}$ 8.0) was added. This economical and expeditious protocol allowed for $\leq 250$ samples to be processed per day and resulted in DNA yields typically of 3 to $10 \mu \mathrm{g} /$ isolate. DNAs were fully resuspended before their concentrations were determined using a fluorometer (Hoefer, Holliston, MA).

In silico PCR restriction fragment length polymorphism marker development. In an initial screen for polymorphic PCR restriction fragment length polymorphism (RFLP) markers, we explored the suitability of cleaved amplified polymorphic sequence markers developed previously through a genetic map project (13). In total, 28 locus-enzyme combinations based on 16 genomic loci were screened for PCR-RFLPs in 22 U.S. F. graminearum isolates representing the known genetic diversity within North America, together with two isolates of $F$. asiaticum. In a second approach, polymorphic PCR-RFLP markers to exploit single-copy nuclear polymorphic (SCNP) DNA in F. graminearum populations were developed based on 10,495 single

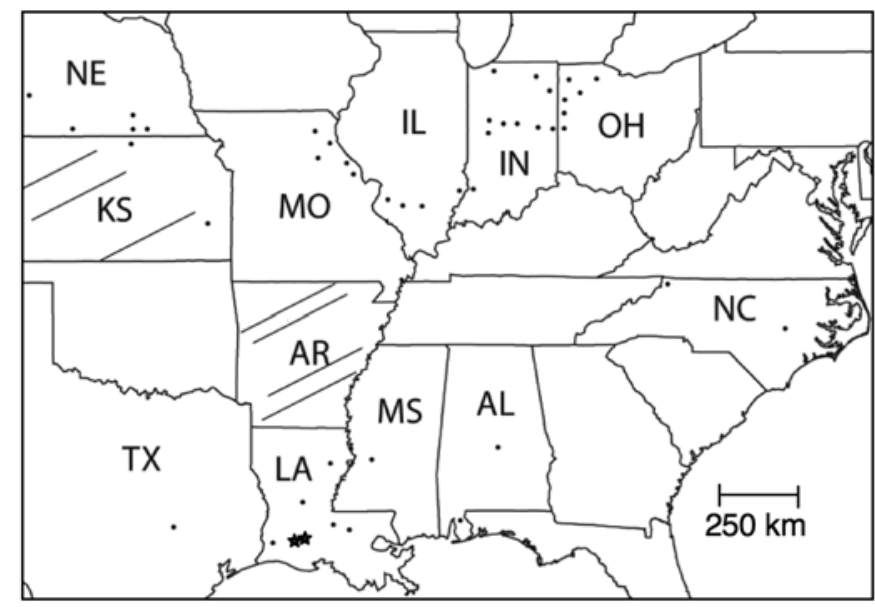

Fig. 1. Approximate county locations in 12 states of the United States from which samples of Fusarium graminearum were obtained. From striped states, location information for (some) samples was not available. Stars designate the Louisiana parishes Acadia and Jefferson-Davis, where Fusarium asiaticum isolates were identified. nuclear polymorphism (SNP) positions detected in the assembly of two sequenced strains PH-1 (=NRRL 31084) (10× sequence coverage) and GZ3639 (=NRRL 29169) (0.4× sequence coverage) (6). In brief, the SNP list was used initially to calculate physical distances between SNPs. SCNP DNA of $\approx 1 \mathrm{~kb}$ was identified across all four chromosomes (13) that were bordered by invariable (monomorphic) sequence. In total, 258 of such sequences were downloaded for $\mathrm{PH}-1$, and in silico restriction patterns for 12 restriction enzymes were established using GENETYX-Mac (version 9.0; Software Development Co., Tokyo). The resulting 3,096 restriction patterns were then visually examined for the presumed number and sizes of fragments for PH-1. Primers were designed for 35 suitable SCNP loci to cover polymorphic genomic regions across all four chromosomes.

Determination of trichothecene type. The trichothecene type for all isolates was determined by multiplex PCR that targeted Tri3 and Tri12 gene sequences (41). This PCR assay allowed for the classification of $F$. graminearum and other B-trichothecene producers as $3 \mathrm{ADON}, 15 \mathrm{ADON}$, or NIV trichothecene type. Isolates classified as 3ADON and 15ADON type accumulate mostly DON in plants whereas the NIV type accumulates mostly NIV.

Molecular genotyping. In addition to trichothecene type, all $F$. graminearum isolates were characterized using 10 PCR-RFLP markers (Table 2). After specific patterns were identified, they were numbered sequentially and stored as line drawings in a Powerpoint file. Each specific pattern was considered a different allele. Because PCR-RFLP products from 96-well DNA sample plates were processed simultaneously, alleles were always assessed in context with other alleles. To avoid potential scoring bias due to isolate origin, individual DNA plates always contained DNA from diverse geographic origins. Repeat isolations from the same wheat spike that often yielded the same genotype (Table 1) were used as positive controls.

Population genetic analyses. Multilocus haplotypes of isolates generated from the specific alleles at 10 PCR-RFLP loci were subjected to two types of analyses. STRUCTURE version 2.3.2 (38), a Bayesian-model-based clustering method that assigns multilocus genotypes probabilistically to user-defined $K$ clusters, was used for inference of population structure. In exploratory runs, we allowed for values of $K$ of 1 to 10 , with 10,000 or 100,000 iterations of Markov Chain Monte Carlo (MCMC) after a burn-in period of 10,000 or 100,000 without any prior information on the origin of each sampled individual. In line with previous studies $(10,15)$ the time-series plots for individual parameters did not change significantly even after short runs. Therefore, we performed final analysis for a burn-in period of 10,000 with 10,000 MCMC iterations. Based on results from further exploratory runs, we decided to use the admixture model that allows for the possibility that each individual may have mixed ancestry. The fraction of ancestry from each cluster is then estimated for each individual. The parameter of individual admixture $\alpha$ was then allowed to be different for individual clusters. During exploratory runs, a variety of values for $\alpha$ was used, varying between 0.001 and 1 . Admixture $\alpha$ was set to 0.25 for the final runs because it placed many individuals into specific clusters while still efficiently excluding individuals with unusual genotypes. Allele frequencies were assumed to be uncorrelated between populations. Otherwise, default settings were used. Despite using a different marker system than in Gale et al. (15), the same settings again seemed best to summarize the data at hand (i.e., burn-in period of 10,000 with 10,000 MCMC iterations, and an admixture model with $\alpha$ different for individual clusters and set to $\alpha=0.25$ ). To help detect the true number of populations, we followed procedures detailed in Evanno et al. (10) with 20 independent runs of $K=1$ to $K=10$. Because variation between runs was minimal at the real $K$, we used the results from a single run as being representative for the specific setting. Analyses of population structure were performed using ARLEQUIN version 3.11 (11). 
Greenhouse experiments. Plant growth conditions, inoculum production, inoculation procedures, and scoring of diseased plants followed previously established protocols (16) with minor modifications. Briefly, in total, 24 isolates encompassing the genetic diversity identified in HB pathogen populations in Louisiana were tested for aggressiveness (spread in wheat spikes) and toxigenic potential in point inoculations of 10 wheat spikes each per isolate and replicate (three replicates total). Toxigenic potential was assessed by gas chromatography/mass spectrometry (GC/MS) to determine trichothecene concentrations in inoculated spikelets harvested 14 days after inoculation (dai). Isolates used in inoculations were grown on mung bean agar in a plate incubator (Conviron, Pembina, ND) under a mixture of fluorescent and near-UV lights at $25^{\circ} \mathrm{C}$ for 7 to 14 days to induce macroconidia production. The inoculum was adjusted to $1 \times 10^{6}$ conidia $/ \mathrm{ml}$ and was stored in microfuge tubes at $-20^{\circ} \mathrm{C}$ up to 3 weeks before inoculation. Triton-X-100 was added at $0.01 \%$ before inoculation. After the inoculum was warmed to room temperature, $20 \mu \mathrm{l}$ of the spore suspension was plated on $1.5 \%$ water agar to assess the germination rate. Only inoculum with an estimated germination rate $>80 \%$ was considered adequate, and data for inoculations with inoculum with a poor germination rate were disregarded. A central spikelet was inoculated with $10 \mu \mathrm{l}$ of inoculum $(10,000$ conidia) and plants were kept first in a mist chamber for $48 \mathrm{~h}$ and then in a greenhouse with no supplemental light. Spread in spikes was assessed at 14 dai. These data and mycotoxin concentrations were analyzed using JMP software (SAS, Cary, NC). These experiments were conducted between January and April 2006.

\section{RESULTS}

Species identification. Conidial morphology of all isolates was assessed during single sporing to place them as members of the $F$. graminearum clade. More detailed analyses were made on the collection from Louisiana. Preliminary molecular genotyping that used the multiplex PCR trichothecene typing method (41) and three $F$. graminearum VNTR markers (42) (L. R. Gale, unpublished) had revealed the collection from Louisiana to be predominantly of the NIV type and genotypically diverse. In total, 154 isolates from the 2003 Louisiana collection (Table 1) with conidial morphologies consistent with the $F$. graminearum clade were typed to species by the MLGT assay. Among those were 03-
33 (NRRL 38393), 03-46 (NRRL 38395), 03-54 (NRRL 38381), 03-65 (NRRL 38369), 03-126 (NRRL 38371), and 03-132 (NRRL 38383 ) that were subsequently described as members of the newly identified Gulf Coast population of $F$. graminearum (41). Among typed isolates, 36 isolates $(23.4 \%)$ were identified as $F$. asiaticum, a species that was previously known only from Asian countries (China, Nepal, Korea, and Japan) and from Brazil (34). The remaining 118 isolates were classified as $F$. graminearum. Members of the Gulf Coast population were also included in this count. An additional five isolates of $F$. asiaticum were later identified in the remaining collection using VNTRs (L. R. Gale, unpublished) and the species identity of all $F$. asiaticum isolates from the United States was further confirmed by diagnostic PCRRFLPs based on a partial histone $\mathrm{H} 3$ gene sequence developed by Suga et al. (43) that distinguishes $F$. graminearum and $F$. asiaticum. A summary of the origin of all $F$. graminearum isolates examined in this study is provided in Table 1.

Because most PCR-RFLP markers developed in this study were based on the genome sequence of $F$. graminearum and did not amplify $F$. asiaticum, we only determined trichothecene type for U.S. isolates of $F$. asiaticum. All isolates of $F$. asiaticum from Louisiana were of the NIV type. In some specific collections, the proportion of $F$. asiaticum isolates was high. In total, 32 of 117 isolates $(27.4 \%)$ from a 2003 collection from the Louisiana State University (LSU) Rice Research Station in Crowley, Acadia Parish was identified as F. asiaticum though, in 2005, only 5 of 84 isolates $(6.0 \%)$ were $F$. asiaticum in a collection from the same location. $F$. asiaticum was also identified from Alexandria (Rapides Parish) in 2003, where this species comprised 4 of the 12 F. graminearum clade isolates $(33.3 \%)$.

PCR-RFLP marker development. In total, 35 primer pairs were screened that were designed based on an in silico approach to detect intraspecific polymorphisms in $F$. graminearum. Collectively, these primers amplified 41,765 bp in strain PH-1, which reportedly contained 451 SNPs between PH-1 and Gz 3639. Based on these 35 primer pairs, 53 locus-enzyme combinations, in all, were tested among a diverse group of $22 \mathrm{~F}$. graminearum isolates from the United States and two isolates of $F$. asiaticum from the United States. Locus-enzyme combinations were assessed for their universality and ease of PCR amplification in $F$. graminearum, and for ease of differentiating different restriction patterns on $1.5 \%$ agarose gels. With the exception of annealing

TABLE 2. Polymorphic polymerase chain reaction restriction fragment length polymorphism markers for population level analyses of $F u$ sarium graminearum

\begin{tabular}{|c|c|c|c|c|c|c|}
\hline Primer name ${ }^{w}$ & Chromosome & Supercontig & Primer sequences & $\mathrm{RE}^{\mathrm{x}}$ & Length (bp) & No. of SNPs \\
\hline \multirow[t]{2}{*}{1389} & 1 & 1 & F:CTTGGAATCCGTTCGGATTT & HaeIII/BamHI & 1,333 & 19 \\
\hline & $\ldots$ & $\ldots$ & R: TGGAGCTGGAGTTTTGACAT & $\ldots$ & $\ldots$ & $\ldots$ \\
\hline \multirow[t]{2}{*}{1401} & 1 & 1 & F: CCCATCCAAGATCGAACTTGT & HinfI & 1,186 & 20 \\
\hline & $\ldots$ & $\ldots$ & R: TGATAATCCCTGGCGTTGTA & $\ldots$ & $\ldots$ & $\ldots$ \\
\hline \multirow[t]{2}{*}{1403} & 1 & 1 & F: GCGAGGACAAGATGTCTTTGA & HaeIII & 1,140 & 13 \\
\hline & $\ldots$ & $\ldots$ & R: AGTATTCCACCAGTGGTCTGC & $\ldots$ & $\ldots$ & $\ldots$ \\
\hline \multirow[t]{2}{*}{1407} & 2 & 5 & F: GTTCAACATTAGACGCCTCGG & HindIII/MspI & 1,192 & 19 \\
\hline & $\ldots$ & $\ldots$ & R: AATCACGAGCTGCGCATAGAT & $\ldots$ & $\ldots$ & $\ldots$ \\
\hline \multirow[t]{2}{*}{$1155^{\mathrm{z}}$} & 2 & 2 & F: ATCAGGTTGGTGCTCGAGTAA & HaeIII & 1,062 & 0 \\
\hline & $\ldots$ & $\ldots$ & R: TGAACAAAACATGGAGGTGG & $\ldots$ & $\ldots$ & $\ldots$ \\
\hline \multirow[t]{2}{*}{1415} & 2 & 2 & F: ATTGACCAGAAGGTCCAGCAT & HaeIII & 1,362 & 11 \\
\hline & $\ldots$ & $\ldots$ & R: ACGCTGCTGAGCATCTCGATA & $\ldots$ & $\ldots$ & $\ldots$ \\
\hline \multirow[t]{2}{*}{1439} & 3 & 9 & F: TTTGAAGCACCCGGTGTTA & HinfI & 991 & 9 \\
\hline & $\ldots$ & $\ldots$ & R: TAAAGTGCACCTCAGGGGCTA & $\ldots$ & $\ldots$ & $\ldots$ \\
\hline \multirow[t]{2}{*}{1441} & 3 & 9 & F: ATTGCTGTCTTTGGCTTCCT & $\operatorname{Taq} \mathrm{I}$ & 1,351 & 15 \\
\hline & $\ldots$ & $\ldots$ & R: TTCGTGAAGCATTGTGCCTT & $\ldots$ & $\ldots$ & $\ldots$ \\
\hline \multirow[t]{2}{*}{1449} & 4 & 4 & F: TCTGTAACTGCATCGCCATT & HinfI & 1,095 & 6 \\
\hline & $\ldots$ & $\ldots$ & R: CCTTTCACATCTCTCCGTCAT & $\ldots$ & $\ldots$ & $\ldots$ \\
\hline \multirow[t]{2}{*}{1457} & 4 & 6 & F: GCGACAAACAACAAGTCGGTT & HaeIII & 1,085 & 12 \\
\hline & $\ldots$ & $\ldots$ & R: TGCATGGGTTGTTGAGACAA & $\ldots$ & $\ldots$ & $\ldots$ \\
\hline Average & $\ldots$ & $\ldots$ & $\ldots$ & $\ldots$ & 1,180 & 13.8 \\
\hline
\end{tabular}

${ }^{\mathrm{w}}$ Naming of primers according to Gale et al. (13).

${ }^{x}$ Restriction enzymes.

y Number of single nucleotide polymorphisms (SNPs) according to Cuomo et al. (6).

${ }^{\mathrm{z}}$ HK_1155 is a previously developed marker (13) and reportedly did not contain SNPs (6). 
temperature that was optimized for each primer pair, a previously published PCR protocol was followed (13). In all, nine locusenzyme combinations were selected by this approach. Together with HK1155, a primer pair that was previously developed during the genetic map project (13), 10 polymorphic markers were developed that are distributed among all four chromosomes (Table 2). Patterns of specific primer pair-enzyme combination were captured as line drawings, which were sequentially numbered and considered to be alleles at a genetic locus. The drawings were used as a reference during scoring.

Assignment of $F$. graminearum isolates to populations. Based on previous studies $(15,41)$, we expected to identify at least two populations of $F$. graminearum among the isolates, the ubiquitous MW15ADON population (15), and the Gulf Coast population (41). STRUCTURE clustered the isolates into three populations (Fig. 2) with the highest increase in probability while further increases in $K$ resulted in additional clusters with much lower increases in posterior probabilities. Additional support for three clusters was obtained using the approach of Evanno et al. (10), assuming $\mathrm{K}=1$ to $\mathrm{K}=10$ (data not shown). Isolates were assigned to a specific population when membership fraction was $P \geq 0.8$. Among the three populations, we recognized the MW15ADON and the Gulf Coast populations and a third population that we named the southern Louisiana population, because it was nearly exclusively found in Louisiana. The distribution and proportion of these three populations in collections from 12 U.S. states is detailed in Table 3. As expected, in the Midwestern states of Illinois, Indiana, Kansas, Missouri, Nebraska, and Ohio, the MW15ADON population was the most widespread, and most isolates $(91.5 \%)$ from that region were placed in that population with $P \geq 0.8$. Most (77.3\%) of the remaining 22 isolates could not be placed into any population according to our selection criteria. Three isolates from Indiana (02-66, 04-46, and 04-58) were classified as belonging to the southern Louisiana population, and two isolates (00-137 from Ohio and 00-165 from Indiana) had genotypes consistent with the Gulf Coast population. The latter two isolates were from a previous study, in which 10 isolates from the Midwest could not be placed into specific populations (15). Among the remaining eight "orphan" isolates, again, three could not be classified into a specific population (00-235, Indiana; 00-179, Ohio; and 00-192, Illinois) while the remaining five were solidly placed into the MW15ADON population, including 00-100 from Missouri with an NIV trichothecene type. In stark contrast to the predominance of the MW15ADON population in the Midwest, $88.2 \%$ of $F$. graminearum isolates of Louisiana were classified as belonging to either the southern Louisiana or Gulf Coast population, with small percentages belonging to the MW15ADON population or remaining unclassified. Among the 37 isolates from Alabama, Arkansas, Mississippi, North Carolina, and Texas, 17 were classified into MW15ADON, 3 into the southern Louisiana population, and 17 were unclassifiable.

Trichothecene type was largely associated with population membership but exceptions were found (Table 4). This study confirms the previous observation that the MW15ADON population predominantly consists of isolates with a 15ADON trichothecene type (15) and that the Gulf Coast population includes isolates with all three trichothecene types (41), though the NIV $(25 \%)$ and especially the 3ADON type $(65.9 \%)$ predominated in this sample of the Gulf Coast population. In contrast, isolates classified as belonging to the southern Louisiana population were predominately of the NIV type $(93.6 \%)$. When the data were further dissected to differentiate among geographic origin of trichothecene type and population membership, a few isolates with a $3 A D O N$ or NIV trichothecene type belonging to the MW15ADON population were identified in Arkansas, Missouri, and North Carolina (i.e., predominantly in the south), whereas NIV isolates in the southern Louisiana and Gulf Coast populations were only identified from Louisiana.

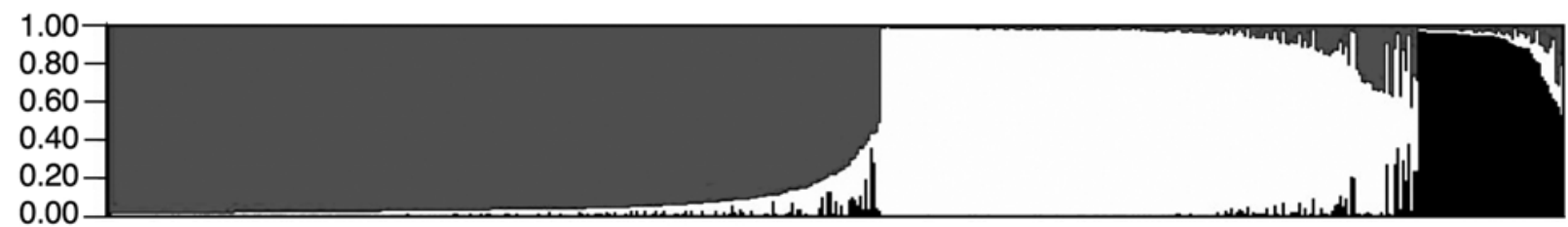

Fig. 2. Population structure of Fusarium graminearum inferred from polymerase chain reaction restriction fragment length polymorphism haplotypes using STRUCTURE 2.3.2. Vertical axis denotes estimated membership fraction in one of three populations, including the Midwestern 15ADON (gray), southern Louisiana (white), and the Gulf Coast (black) populations. The horizontal axis consists of a single vertical bar for each of 534 isolates, arranged according to membership fraction. Isolates were assigned to a specific population when membership fraction $\geq 0.8$.

TABLE 3. Proportional assignment of Fusarium graminearum genotypes into three populations ${ }^{\mathrm{x}}$

\begin{tabular}{|c|c|c|c|c|c|}
\hline State & No. of isolates & Midwestern 15ADON & Southern Louisiana & Gulf Coast & Overall assignment $\mathrm{t}^{\mathrm{y}}$ \\
\hline Alabama & 2 & 1 & 0 & 0 & 1 \\
\hline Illinois & 40 & 0.975 & 0 & 0 & 0.975 \\
\hline Kansas & 21 & 0.857 & 0 & 0 & 0.857 \\
\hline Louisiana & 237 & 0.046 & 0.705 & 0.177 & 0.928 \\
\hline Missouri & 50 & 0.920 & 0 & 0 & 0.920 \\
\hline Mississippi & 1 & 1 & 0 & 0 & 1 \\
\hline Ohio & 40 & 0.925 & 0 & 0 & 0.925 \\
\hline Texas & 3 & 0.333 & 0 & 0 & 0.333 \\
\hline Others ${ }^{\mathrm{z}}$ & 11 & 0.545 & 0 & 0.182 & 0.727 \\
\hline Total no. & 534 & 0.498 & 0.324 & 0.082 & 0.904 \\
\hline
\end{tabular}

${ }^{\mathrm{x}}$ Genotypic polymerase chain reaction restriction fragment length polymorphism data for F. graminearum isolates was analyzed using STRUCTURE 2.3.2. (38), similar to an approach previously described (15). The collection could be organized into three main genetic clusters that were acknowledged as separate populations. Membership was assumed if the probability of an isolate belonging to a specific population was $\geq 0.8$.

${ }^{y}$ Proportion of isolates that could be assigned to one of the three defined populations with $P \geq 0.8$.

${ }^{\mathrm{z}}$ Ten Midwestern isolates of $F$. graminearum that in a previous STRUCTURE analysis (15) could not be placed into a specific population; plus PH-1, the sequenced standard strain (6). 
Population genetic analyses. ARLEQUIN was used to further characterize the populations at an intra- and interpopulation level. At the outset, two or more isolates that were isolated from the same spike and displayed the same genotype were counted only once (Table 1) to disregard repeat isolations. Therefore, the search for shared genotypes within populations only took into account distinct locations and points in time. Among 266 members of the MW15ADON population, 240 distinct genotypes were identified. Nineteen genotypes were shared predominantly by two isolates (range 2 to 4 ; average 2.37), with only three pairs originating from the same location (field). In contrast, only 88 genotypes were detected among the 173 isolates of the southern Louisiana population. The 26 genotypes that were shared had an average of 4.27 members (range: 2 to 17). The same genotypes were generally found over space or time and, therefore, were persistent. For example, the most frequent genotype in the southern Louisiana population, represented by 17 NIV-type isolates, was identified in several years (2003, 2005, and 2007) and in various locations in Jefferson Davis and Acadia Parishes. Most shared genotypes only included isolates with the same trichothecene type, though four shared genotypes contained more than one trichothecene type. Among 44 isolates from the Gulf Coast population, 28 genotypes were identified. Of these, six were shared (range: 2 to $10 \mathrm{mem}-$ bers, average 3.5 ) though only one genotype was dominant, with 10 members that all consisted of the 3ADON trichothecene type. The latter genotype was identified from multiple years (2003, 2005, and 2007) and from the parishes of Acadia and Central Acadia.

Analysis of molecular variance of 483 isolates from three populations indicated that $38.51 \%$ of variation was due to differences between populations. This is an average across all loci. When $\mathrm{F}_{\mathrm{ST}}$ values per polymorphic locus between populations were calculated, values were 0.088 to 0.755 (data not shown). The population pair Gulf Coast-southern Louisiana displayed the highest $\mathrm{F}_{\mathrm{ST}}$ value across population pairs $\left(\mathrm{F}_{\mathrm{ST}}=0.5\right)$, even though these populations coexist in the same habitat (data not shown). All population pairs were significantly different from each other, suggesting little or no gene flow between the populations. For intrapopulation variables measured, comparisons between populations regarding diversity measures can be summarized as follows: MW15ADON > southern Louisiana > Gulf Coast (Table 5). A final analysis at the molecular level evaluated random mating within populations. Pairwise linkage disequilibrium was evaluated in ARLEQUIN by measuring deviations from random association between alleles at two different loci. In the MW15ADON population, 8 of 45 locus pairs $(17.7 \%)$ differed significantly from frequency expectations of allele combinations in randomly mating populations in the southern Louisiana population (9 of 45, 20\%) and in the Gulf Coast population (4 of $36,11 \%$ ). Based on physical locations of locus pairs and their estimated genetic distance based on the genetic map (13), significant locus pairs were not genetically linked, with only two exceptions (data not shown).

Aggressiveness and toxigenic potential. Aggressiveness and toxigenic potential were assessed for 24 isolates that encompassed the genetic variation present in the $F$. graminearum clade from Louisiana (Fig. 3). Means for each of the isolates are displayed in Figure 3. For statistical analysis, data were grouped. In a first analysis, overall spread in spikes and mycotoxin accumu-

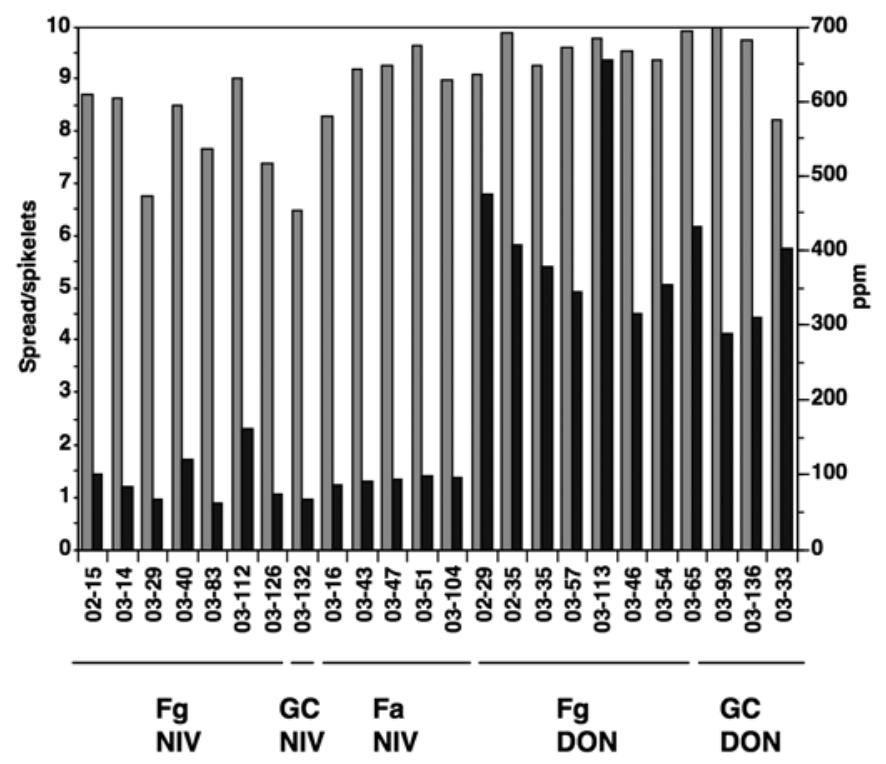

Fig. 3. Average spread in spikelets (maximum $=10)$ in point-inoculated wheat spikes of the susceptible cv. Norm (gray) and average trichothecene mycotoxin accumulation in ppm in inoculated spikelets (black) in 24 isolates of the Fusarium graminearum clade from Louisiana, representing the genetic diversity found in the state. Each value represents the average of 10 spikes per inoculation with three repetitions. $F g=F$. graminearum, $\mathrm{GC}=$ Gulf Coast population of $F$. graminearum, $F a=F$. asiaticum, NIV $=$ nivalenol, and DON = deoxynivalenol.

TABLE 4. Organization of trichothecene types in three populations of Fusarium graminearum and their geographic distribution

\begin{tabular}{|c|c|c|c|c|c|c|}
\hline \multirow[b]{3}{*}{ Type $^{y}$} & \multicolumn{6}{|c|}{ Population $^{z}$} \\
\hline & \multicolumn{2}{|r|}{ Midwestern 15ADON } & \multicolumn{2}{|c|}{ Southern Louisiana } & \multicolumn{2}{|c|}{ Gulf Coast } \\
\hline & Proportion (no.) & States & Proportion (no.) & States & Proportion (no.) & States \\
\hline $15 \mathrm{ADON}$ & $0.951(253)$ & $\begin{array}{l}\text { Alabama, Arkansas, Illinois, Indiana, Kansas, } \\
\text { Louisiana, Missouri, Mississippi, North Carolina, } \\
\text { Nebraska, Ohio, Texas }\end{array}$ & $0.041(7)$ & $\begin{array}{l}\text { Arkansas, Louisiana, } \\
\text { Indiana }\end{array}$ & $0.091(4)$ & $\begin{array}{l}\text { Louisiana, Indiana, } \\
\text { Ohio }\end{array}$ \\
\hline 3ADON & $0.023(6)$ & Arkansas, Louisiana & $0.023(4)$ & Arkansas, Louisiana & $0.659(29)$ & Louisiana \\
\hline NIV & $0.026(7)$ & Arkansas, Louisiana, Missouri, North Carolina & $0.936(162)$ & Louisiana & $0.250(11)$ & Louisiana \\
\hline Total (no.) & $(266)$ & $\ldots$ & $(173)$ & $\ldots$ & $(44)$ & $\ldots$ \\
\hline
\end{tabular}

y Trichothecene type was determined according to Starkey et al. (41). NIV = nivalenol.

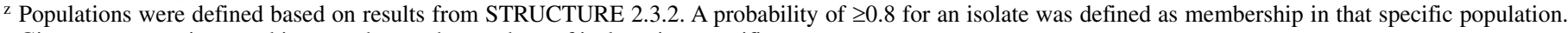
Given are proportions, and in parentheses, the numbers of isolates in a specific category.

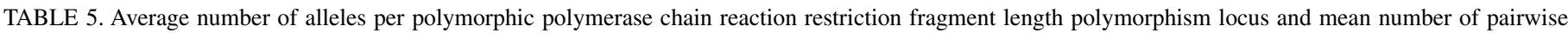
differences between isolates of specific populations and expected heterozygosity (standard deviation in parentheses)

\begin{tabular}{|c|c|c|c|c|}
\hline Population & Sample size & No. of alleles per locus ${ }^{\mathrm{z}}$ & Mean no. of pairwise differences ${ }^{z}$ & Expected heterozygosity ${ }^{z}$ \\
\hline Midwestern 15ADON & 266 & $4.3(1.42)$ & $4.89(2.39)$ & $0.51(0.13)$ \\
\hline Southern Louisiana & 173 & $3.2(0.98)$ & $3.46(1.77)$ & $0.35(0.14)$ \\
\hline Gulf Coast & 44 & $2.9(0.78)$ & $2.29(1.25)$ & $0.28(0.11)$ \\
\hline
\end{tabular}

${ }^{\mathrm{z}}$ Calculated in ARLEQUIN 3.1 (11). 
lation in inoculated spikelets was compared between NIV and DON producers (Table 6). Overall, DON producers produced approximately four times as much toxin as the NIV producers, while DON producers also spread significantly more, although that difference was not as pronounced. In a second analysis, aggressiveness and toxigenic potential were compared between NIV types of $F$. graminearum and of $F$. asiaticum (Table 6). Infections with $F$. asiaticum isolates spread more and accumulated more NIV in plants, although only spread was significantly different between the two species.

\section{DISCUSSION}

We employed multi-year and large-scale sampling strategies combined with genotyping based on sophisticated molecular markers to not only unearth significant population structure within $\mathrm{HB}$ pathogens in the United States but also ascertain the presence of significant populations of NIV-producing F. graminearum and $F$. asiaticum in the United States, a toxin, which hitherto was assumed to be absent from U.S. grain.

SCNP marker development. VNTR markers have been developed previously for $F$. graminearum (42) and have been effectively used for population analyses of $F$. graminearum and $F$. asiaticum populations in North America and Asia $(18,19,48)$. Here, we present an alternative, PCR-RFLP-based marker system that is based on SCNP sequences. These markers can be useful when VNTR analysis is technologically not feasible or not desirable; for example, if homoplasy, mutational convergence, mutation rate difference, or selective neutrality $(35,55)$ is a concern.

The availability of two genome sequences of the same species allowed us to undertake an in silico approach for marker development that not only substantially economized screening time and cost but also allowed for the strategic positioning of markers across the whole genome. SNP positions in the genome of two F. graminearum strains, $\mathrm{PH}-1$ and Gz 3639, were previously determined to be highly localized, with $50 \%$ of SNPs identified in only $13 \%$ of the genome sequence (6). The 35 primer pairs that we eventually developed for screening encompassed highly polymorphic regions of the genome, with reportedly $1.1 \%$ SNPs compared with an average density of $0.029 \%$ SNPs across the whole genome. Due to the polymorphic nature of targeted regions, universal amplification was a concern, although we had positioned primers in presumably monomorphic regions. Still, among 35 tested primer pairs, only 17 resulted in a PCR product for all isolates used in the screening, though this number increased to 26 when data from the two $F$. asiaticum strains were disregarded. Of 10 loci eventually chosen for population level analyses, six primer pairs amplified sequences for all $F$. graminearum isolates but not for $F$. asiaticum and four primer pairs amplified sequences for all 24 isolates used in the screening. NRRL 36905, the type strain of $F$. gerlachii (41), a close relative of $F$. graminearum, also generated data for all ten loci (data not shown). Therefore, the marker system is restricted to population level analysis of $F$. graminearum and very closely related allies. Based on the moderate number of alleles per locus and the low number of shared genotypes in the MW15ADON population, our PCR-RFLP system allows for excellent genotypic resolution without excessive polymorphisms.

F. asiaticum. This is the first report of $F$. asiaticum in the United States. At some locations and in some years, its proportion in the pathogen population was relatively high (up to one-third of the population) but additional sampling is necessary to confirm its persistence or spread in the United States. Rudimentary analysis of the intraspecific variation of the U.S. population of $F$. asiaticum suggests low levels of genetic diversity, which would be consistent with the premise of an introduced population. Whereas Chinese and Japanese populations of $F$. asiaticum typically contain isolates with either the 3ADON or the NIV type (18, $19,56)$, the U.S. population of $F$. asiaticum only comprised the NIV type. Intriguingly, a predominance $(96.8 \%)$ of the NIV type compared with DON type was also observed in southern Korean populations of $F$. asiaticum (21). We are currently reanalyzing the U.S. F. asiaticum population with Suga's (42) VNTR markers in an attempt to determine its original geographic origin, estimate diversity levels in the U.S. population of F. asiaticum, and compare it with other geographic populations of $F$. asiaticum. It is also advised here that the spatial and temporal dynamics of $F$. asiaticum in the United States should be monitored, because results from greenhouse experiments suggest a higher aggressiveness of NIV-type U.S. F. asiaticum compared with NIV-type U.S. F. graminearum.

Gulf Coast population of $\boldsymbol{F}$. graminearum. Previously (41), eight isolates were recognized as members of the U.S. Gulf Coast population of $F$. graminearum. Two of the isolates originated from leatherleaf fern (Rumohra adiantiformis) grown commercially in Florida $(32,34)$, while six Gulf Coast isolates were identified from the present Louisiana collection. Though divergence of the Gulf Coast population from $F$. graminearum was observed for some genes, the $F$. graminearum assignment of the Gulf Coast population was done conservatively due to shared polymorphisms in some of the sequenced genes (41). Here, based on results from STRUCTURE, 44 isolates were recognized as members of the Gulf Coast population. Five of the six Louisiana Gulf Coast isolates of Starkey were correctly identified also, though 03-126 (NRRL 38371) clustered with the MW15ADON population and was considered here to be a member of the latter population. Although the NIV type was not uncommon in the Gulf Coast population (25\%), the majority of isolates displayed a $3 \mathrm{ADON}$ type that was also characteristic of the clonal genotype that represented $25 \%$ of the Gulf Coast population. Although a higher diversity for trichothecene type was observed in the Gulf Coast population than for the other two populations of $F$. graminearum investigated here, within-population diversity values based on PCR-RFLPs were substantially lower than what was observed for the other two populations. Though this result may be partly due to the predominance of one clonal genotype, this observation may also be indicative of the Gulf Coast population being a newer or introduced population. Individuals belonging to this population were also isolated from fern originating in Florida; therefore, a possible center of diversity

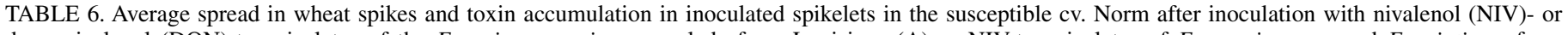

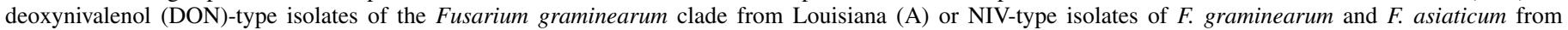
Louisiana (B) ${ }^{\mathrm{w}}$

\begin{tabular}{|c|c|c|c|c|c|}
\hline \multicolumn{3}{|c|}{ A } & \multicolumn{3}{|c|}{ B } \\
\hline Trichothecene type ${ }^{x}$ & Spread $^{\mathrm{y}}$ & Toxin in $\mathrm{ppm}^{\mathrm{z}}$ & F. graminearum clade species ${ }^{\mathrm{x}}$ & Spread $^{\mathrm{y}}$ & NIV in $\mathrm{ppm}^{\mathrm{z}}$ \\
\hline NIV (13) & $8.38 \mathrm{a}$ & $99.1 \mathrm{a}$ & $F$. graminearum $(8)$ & $7.96 \mathrm{a}$ & $86.6 \mathrm{a}$ \\
\hline DON (11) & $9.48 \mathrm{~b}$ & $388.8 \mathrm{~b}$ & F. asiaticum (5) & $9.05 \mathrm{~b}$ & $119.3 \mathrm{a}$ \\
\hline
\end{tabular}

${ }^{\text {w }}$ Values within a column followed by different letters are significantly different by Students $t$ test at $P=0.05$.

${ }^{x}$ Numbers in parentheses indicates number of isolates tested.

y Symptoms assessed in ten spikelets total located above and below, and including the inoculated spikelet 14 dai.

${ }^{\mathrm{z}}$ NIV for NIV types, DON for DON types. Toxins were measured by gas chromatography/mass spectrometry in inoculated spikelets 14 days after inoculation. 
may not be located in Louisiana and the population may not have evolved on cereals.

Southern Louisiana population of $\boldsymbol{F}$. graminearum. One of the major outcomes of this study was the identification and description of a new population of $F$. graminearum, the southern Louisiana population that dominates the HB pathogen population in sampled regions of Louisiana. We show here that this population is omnipresent in south-central Louisiana and that this population predominantly (93.6\% of isolates) consists of the NIV type.

Distribution of species and trichothecene types. It has previously been recognized that the $F$. graminearum clade species composition appears to be location and, perhaps, host dependent $(21,32)$. In the Asian countries of China, Japan, and Korea, both $F$. graminearum and $F$. asiaticum are generally present and $F$. asiaticum isolates are either DON or NIV types, whereas the NIV type within $F$. graminearum appears to be very rare. Clines were observed not only for the specific geographic distributions and ratios of $F$. asiaticum and $F$. graminearum $(21,43,51,56)$ but also for trichothecene type ratios within $F$. asiaticum. Although, in some studies, the NIV type predominated over the 3ADON type $(21,43)$, a dramatic gradient in trichothecene type in Chinese $F$. asiaticum was identified (51) that could not be correlated to cropping system or climatic conditions, though it was hypothesized that DON producers (within $F$. asiaticum) may be more aggressive on wheat. Similarly, in Korea (21), a predominance of lineage 6 of $F$. graminearum (equivalent to $F$. asiaticum) over lineage 7 of $F$. graminearum (equivalent to $F$. graminearum) in southern Korea was hypothesized to be due to a superior fitness on rice.

Although the underlying factors for species and trichothecene type distribution are unknown, the occurrence of $F$. asiaticum and NIV-type strains of $F$. graminearum in Louisiana neatly overlaps with rice-growing areas in Louisiana. Acadia and Jefferson Davis Parishes that yielded the majority $(87.9 \%)$ of isolates from Louisiana in our collection ranked first and second, respectively, for rice production in LA and, together, produce one-third of rice in that state (information available from LSU AgCenter). Whether this is coincidence and is simply due to the fact that the climate that is beneficial for rice production may also favor NIV strains, whether rice is particularly important in the life cycle of NIV-type strains of $F$. graminearum clade species, or whether $F$. asiaticum was initially introduced into the United States on rice shall remain hypotheses.

MW15ADON population. As expected, isolates collected from Midwestern states between 2001 and 2007 belonged overwhelmingly to the MW15ADON population and displayed a 15ADON trichothecene type. This observation mirrors results from the 1999 to 2000 collection of U.S. F. graminearum (15).

Greenhouse assessments. In our greenhouse experiments, NIV-type isolates spread significantly less than DON-type isolates, which would indicate that DON types generally are more aggressive on wheat, supporting previous research (23). The difference between DON and NIV types was even more significant in the amount of toxin produced. Although the spread of DON-type isolates was only $13 \%$ more than the NIV-type isolates, DON types, on average, caused the accumulation of four times as much toxin as NIV types, which may be due to the higher cytotoxicity of NIV. As discussed above, NIV-type $F$. asiaticum isolates from Louisiana were significantly more aggressive than NIV-type $F$. graminearum and accumulated a higher level of toxin (though this difference was not significant). All isolates were considered aggressive. We conclude that aggressiveness and toxigenic potential is, in part, a population or group feature (48) and that the type of toxin can be a determinant of aggressiveness. A previous study came to different conclusions (16), stating that aggressiveness and mycotoxin accumulation are strain-specific features and that the amount of toxin, not the type of toxin, is a determinant of aggressiveness. In that study, several isolates were poorly pathogenic and also did not accumulate much toxin, which led to large variation in aggressiveness and toxin accumulation between strains. Because our study produced more homogeneous results, it can be speculated that some of the strains were either attenuated during extensive storage or that inoculum was not of high quality. In initial phases of our work, low scores of both spread and toxin concentrations were always due to poor inoculum quality. Therefore, determining the germination rate of inoculum in vitro was deemed absolutely necessary. For example, conidia of Louisiana isolates had a diminished survival rate at $-20^{\circ} \mathrm{C}$, which is otherwise a suitable short-term storage regime for Midwestern strains.

Unassigned or atypical isolates. Altogether, $9.55 \%$ of isolates could not be placed into a specific populations with $P>0.8$. Although many of these isolates could be recombinants between the known populations or variants of populations with unusual allelic combinations, STRUCTURE will "fit" all isolates into $K$ predefined populations; therefore, our collection may also contain isolates of additional, unidentified populations. Though the population identity of the unassigned isolates was not resolved here, valuable observations may still be extracted from these data. Although Louisiana was the only state in which members of all three populations of $F$. graminearum (and $F$. asiaticum) were identified, only a relatively small proportion of isolates $(7.2 \%)$ could not be placed into a specific population. This observation implies that individuals of different populations (and species) only infrequently, if at all, recombine in Louisiana. Conversely, almost half of isolates (45.9\%) from the southern states of Alabama, Arkansas, Mississippi, North Carolina, and Texas could not be placed into populations. The collection from these states was admittedly small, with 37 isolates, which also reflects that, typically, $F$. graminearum is less frequently isolated from these states. Nevertheless, this result allows for the hypothesis that recombination between populations may take place in the southern region which, therefore, may contain hybrid zones. Hybrid zones have been described as "narrow regions in which genetically distinct populations meet, mate, and produce hybrids" (2). The fact that, south and north of these hypothetical hybrid zones, isolates can generally be placed into their specific population then allows for the hypothesis that gene flow between the populations from Louisiana and the Midwest is impeded. One explanation could be that these hypothetical hybrid zones may also act as hybrid sinks, in which gene flow may be hindered by a much reduced fitness of the hybrids (2).

For isolates that were assigned to specific populations, trichothecene type was generally correlated with population assignment, though not without exceptions. It is interesting to note that members of specific populations with atypical trichothecene types were identified especially in Louisiana and Arkansas. If one hypothesizes that specific populations were originally diverse for trichothecene type and that the isolates with atypical trichothecene types are remnants of this diversity, then the assumed loss of diversity might be due to genetic drift or selection within populations. Alternatively, trichothecene type may have introgressed. Opportunely, environmental conditions in 2008 and 2009 were conducive to HB disease development in Arkansas, allowing us to establish a significant collection from that state. This collection may provide the opportunity to directly address the above questions and hypotheses regarding atypical or unassigned isolates.

Clonality, recombination, and mixed reproductive systems. Only rarely was the same genotype identified more than once in the MW15ADON population whereas, in Louisiana, shared genotypes were commonly observed in both the southern Louisiana and Gulf Coast populations. Though it is possible that isolates with the same PCR-RFLP genotype are not clonally related, the fact that the three populations were characterized by different genotype composition profiles and that many shared genotypes 
displayed the same trichothecene type allows for the general conclusion that asexual proliferation is of epidemiological significance in Louisiana. This observation may then relate to those of Mitter et al. (30), who compared the prevalence of spore types in HB inoculum in North Dakota and in New South Wales, Australia. Ascospores predominated in North Dakota while conidia were found to be the dominant HB inoculum in New South Wales. Observations of higher perithecium production by the U.S. isolates in vitro was correlated with the fact that the production of perithecia on crop residue is critical to the winter survival of $F$. graminearum in the Midwestern United States Conversely, in the mild winters of the Australian wheat-growing areas, the pathogen mostly survives vegetatively in crop debris, and perithecia are reportedly rare (27). Our observation of a persistent clonal contingent in Louisiana may then imply vegetative survival between growing seasons or continuous host availability. A clonal contingent has also been found in $F$. asiaticum pathogen populations from rice in Korea (21).

Despite the evidence that clonality is of epidemiological importance in the southern Louisiana and Gulf Coast populations, both populations also appear outcrossed. Within all three populations, most locus pairs ( 80 to $89 \%$ ) were in equilibrium and, therefore, not different from expectations for randomly mating populations. Together with the occurrence of persistent clones in both the Gulf Coast and southern Louisiana populations, these two populations may then be classified as having a mixed reproductive system. According to McDonald and Linde (25), pathogens with mixed reproductive systems pose the "highest risk of evolution." The fact that favorable genotypes may be generated through outcrossing, which then may spread as clones in space and persist in time, should be considered when HB pathogen populations are put under selective constraints (e.g., specific management systems such resistant cultivars or fungicides). Due to these specific population characteristics, further monitoring of the Louisiana population for dominant clones is deemed advisable.

Nivalenol. Among trichothecenes, NIV has been called the "neglected toxin" (36), which may be attributed to the fact that, on a global scale, current and past levels of NIV contamination in food or feed have been generally substantially lower than DON levels, as is exemplified in the compilation of global data of mycotoxin contamination of cereal grains and animal feed by Placinta et al. (37). Exceptions were The Netherlands, Korea, Vietnam, China, Japan, New Zealand, and Brazil that reported comparable levels of DON and NIV. Reports from several countries, including the United States, did not measure or mention NIV. A first study of natural occurrence of various Fusarium toxins in cereals on a global scale also reported a high incidence and generally high concentrations of NIV in Asian samples, though the authors emphasized that contamination with NIV is globally prevalent (44). Recently, a European task force determined mycotoxin occurrence and concentrations in several thousand samples of food and food raw materials from 12 European countries (40). Whereas $57 \%$ of tested samples were positive for DON, $16 \%$ were positive for NIV, though possible co-contamination with NIV and DON in samples was not measured or reported.

Other than the outcome of an epidemiological study in China that revealed a correlation between high levels of NIV in foods and incidence of cancer of the esophagus and gastric cardia (17), not much is known about the specific toxic effects of long-term NIV exposure in humans or the comparative toxicity of NIV and DON. Nevertheless, extrapolations of their adverse health effects and their comparative toxicity can be made from experiments using human and animal cell lines that seek to determine mechanisms of in vitro toxicity of trichothecenes. Generally, cell metabolism and cell proliferation were significantly more inhibited by NIV than by DON, indicative of higher cytotoxicity $(9,12,28)$. Due to the assumed higher toxicity of NIV compared with DON, the European Scientific Committee on Food set a lower limit for temporary tolerable daily intake (t-TDI) for NIV $(0.7 \mu \mathrm{g} / \mathrm{kg}$ of bodyweight) than for the DON (1 $\mu \mathrm{g} / \mathrm{kg}$ of bodyweight) (40). In the United States, the Food and Drug Administration has issued advisory levels to provide guidance to the grain industry concerning levels of DON present in food or feed and to provide an adequate margin of safety to protect human and animal health. The DON advisory level for finished wheat products is currently $1 \mathrm{ppm}$. Information on additive or interactive toxicity of DON and NIV generally seems to be lacking but no interaction between DON and NIV was reported for porcine-blood proliferation (22).

Although trichothecene mycotoxins can be identified by chromatography and MS in specialized laboratory settings, they are not suitable for routine sample measurements in the field. GIPSA, which is part of the USDA Marketing and Regulatory Programs, maintains a list of (currently 21) performance-verified rapid test kits for DON analysis for certification of DON levels in grain and commodities under the United States Grain Standards Act. These tests are based on enzyme-linked immunosorbent assays, lateral flow strips, fluorescence polarization, microtiter well-plate assay, and rapid enzyme immunoassay. Currently, none of the GIPSA performance-verified rapid test kits detects NIV. In the past, lack of antibodies that cross-react with NIV has hampered the development of immunoassays. Recently, a few reports describe the development of assays and kits that may detect both NIV and DON, following the tenet that multiple mycotoxins may occur in food or feed stuff, which should preferably be measured simultaneously (24,53). A case in point are the GC/MS measurements from the naturally infected Wheat Variety Test by the Louisiana Experiment Station at Crowley, LA in 2005, in which both DON and NIV concentrations were assessed. Among 174 entries, the average value for DON was $0.128 \mathrm{ppm}$ (range: 0 to $1.3 \mathrm{ppm}$ ) and for NIV was $0.298 \mathrm{ppm}$ (range: 0 to $1.5 \mathrm{ppm}$ ). The highest combined value for the two toxins was $2.46 \mathrm{ppm}$.

Summary. It has been previously suggested that the NIV type of $F$. graminearum is rare in the United States, so that the only way for the NIV type with adequate fitness to become established in North America would be by migration and introgression into the resident DON populations (8). This study demonstrates that the United States already is home to NIV F. graminearum clade populations that appear established (NIV $F$. graminearum) and introduced (NIV F. asiaticum) but that are currently restricted to a relatively small area of the U.S. small-grain-growing region. The present study, which reports on the detection, characterization, and distribution of the newly described southern Louisiana population of $F$. graminearum, adds to our growing knowledge of genetically diverse populations of $F$. graminearum, including the emerging populations in North America, i.e., the Upper Midwest (15) and Canada (48), as well as the presence of other $F$. graminearum clade species (41). Collectively, these studies have revealed significant $F$. graminearum clade diversity in North America that requires active surveillance of these pathogens and their toxins.

\section{ACKNOWLEDGMENTS}

This material is based upon work supported by the USDA under agreement no. 59-0790-7-074. This is a cooperative project with the United States Wheat \& Barley Scab Initiative. We thank K. Hilburn, USDA-ARS, Cereal Disease Laboratory, and former University of Minnesota students J. Lorenz and L. O'Leary for excellent technical help; and Y. Dong, Mycotoxin Laboratory, University of Minnesota, for GC/MS mycotoxin analysis of infected plant samples.

\section{LITERATURE CITED}

1. Bai, G.-H., and Shaner, G. E. 1994. Scab of wheat: Perspective and control. Plant Dis. 78:760-766.

2. Barton, N. H., and Hewitt, G. M. 1985. Analysis of hybrid zones. Annu. 
Rev. Ecol. Syst. 16:113-148.

3. Bowden, R. L., Leslie, J. F., Lee, J., and Lee, Y.-W. 2006. Cross fertility of lineages in Fusarium graminearum (Gibberella zeae). Pages 54-60 in: The Global Fusarium Initiative for International Collaboration: A Strategic Planning Workshop. T. Ban, J. M. Lewis, and E. E. Phipps, eds. CIMMYT, El Batán, Mexico.

4. Correll, J. C., Klittich, C. J. R., and Leslie, J. F. 1987. Nitrate nonutilizing mutants of Fusarium oxysporum and their use in vegetative compatibility tests. Phytopathology 77:1640-1646.

5. Cowger, C., and Sutton, A. L. 2005. The southeastern U.S. Fusarium head blight epidemic of 2003. Plant Health Progress. Online publication 10.1094/PHP-2005-1026-01-RS

6. Cuomo, C. A., Güldener, U., Xu, J.-R., Trail, F., Turgeon, B. G., Di Pietro, A., Walton, J. D., Ma, L.-J., Baker, S. E., Rep, M., Adam, G., Antoniw, J., Baldwin, T., Calvo, S., Chang, Y.-L., DeCaprio, D., Gale, L. R., Gnerre, S., Goswami, R. S., Hammond-Kosack, K., Harris, L. J., Hilburn, K., Kennell, J. C., Kroken, S., Magnuson, J. K., Mannhaupt, G., Mauceli, E., Mewes, H.-W., Mitterbauer, R., Muehlbauer, G., Münsterkötter, M., Nelson, D., O’Donnell, K., Ouellet, T., Qi, W., Quesneville, H., Roncero, M. I. G., Seong, K.-Y., Tetko, I. V., Urban, M., Waalwijk, C., Ward, T. J., Yao, J., Birren, B. W., and Kistler, H. C. 2007. The Fusarium graminearum genome reveals a link between localized polymorphism and pathogen specialization. Science 317:1400-1402.

7. Desjardins, A. E. 2006. Fusarium Mycotoxins Chemistry, Genetics and Biology. American Phytopathological Society Press, St. Paul, MN.

8. Desjardins, A. E., Busman, M., Manandhar, G., Jarosz, A. M., Manandhar, H. K., and Proctor, R. H. 2008. Distribution of the mycotoxins nivalenol and deoxynivalenol in naturally and experimentally infected maize. J. Agric. Food Chem. 56:5428-5436.

9. Eriksen, G. S., Pettersson, H., and Lundh, T. 2004. Comparative cytotoxicity of deoxynivalenol, nivalenol, their acetylated derivatives and de-epoxy metabolites. Food Chem. Toxicol. 42:619-624.

10. Evanno, G., Regnaut, S., and Goudet, J. 2005. Detecting the number of clusters of individuals using the software STRUCTURE: A simulation study. Mol. Ecol. 14:2611-2620.

11. Excoffier, L., Laval, G., and Schneider, S. 2005. Arlequin ver. 3.0: An integrated software package for population genetics analysis. Evol. Bioinf. Online 1:47-50.

12. Fornelli, F., Minervini, F., and Mulè, G. Cytotoxicity induced by nivalenol, deoxynivalenol, and fumonisin B1 in the SF-9 insect line. In Vitro Cell. Dev. Biol. Anim. 40:166-171.

13. Gale, L. R., Bryant, J. D., Calvo, S., Giese, H., Katan, T., O’Donnell, K., Suga, H., Taga, M., Usgaard, T. R., Ward, T. J., and Kistler, H. C. 2005. Chromosome complement of the fungal plant pathogen Fusarium graminearum based on genetic and physical mapping and cytological observations. Genetics 171:985-1001.

14. Gale, L. R., Chen, L.-F., Hernick, C. A., Takamura, K, and Kistler, H. C. 2002. Population analysis of Fusarium graminearum from wheat fields in eastern China. Phytopathology 92:1315-1322.

15. Gale, L. R., Ward, T. J., Balmas, V., and Kistler, H. C. 2007. Population subdivision of Fusarium graminearum sensu stricto in the Upper Midwestern United States. Phytopathology 97:1434-1439.

16. Goswami, R. S., and Kistler, H. C. 2005. Pathogenicity and in planta mycotoxin production among members of the Fusarium graminearum species complex on wheat and rice. Phytopathology 95:1397-1404.

17. Hsia, C. C., Wu, Z. Y., Li, Y. S., Zhang, F., and Sun, Z. T. 2004. Nivalenol, a main Fusarium toxin in dietary foods from high-risk areas of cancer of esophagus and gastric cardia in China, induced benign and malignant tumors in mice. Oncol. Rep. 12:449-456.

18. Karugia, G. W., Suga, H., Gale, L. R., Nakajima, T., Tomimura, K., and Hyakumachi, M. 2009. Population structure of the Fusarium graminearum species complex from a single Japanese wheat field sampled in two consecutive years. Plant Dis. 93:170-174.

19. Karugia, G. W., Suga, H., Gale, L. R., Nakajima, T., Ueda, A., and Hyakumachi, M. 2009. Population structure of Fusarium asiaticum from two Japanese regions and eastern China. J. Gen. Plant Pathol. 75:110-118.

20. Koenig, R. L., Ploetz, R. C., and Kistler, H. C. 1997. Fusarium oxysporum f. sp. cubense consists of a small number of divergent and globally distributed clonal lineages. Phytopathology 87:915-923.

21. Lee, J., Chang, I. Y., Kim, H., Yun, S.-H., Leslie, J. F., and Lee, Y.-W. 2009. Genetic diversity and fitness of Fusarium graminearum populations from rice in Korea. Appl. Environ. Microbiol. 75:3289-3295.

22. Luongo, D., De Luna, R., Russo, R., and Severino, L. 2008. Effects of four Fusarium toxins (fumonisin $\mathrm{B}_{1}, \alpha$-zearalenol, nivalenol and deoxynivalenol) on porcine whole-blood cellular proliferation. Toxicon 52:156-162.

23. Maier, F. J., Miedaner, T., Hadeler, B., Felk, A., Salomon, S., Lemmens, M., Kassner, H., and Schäfer, W. 2006. Involvement of trichothecenes in fusarioses of wheat, barley, and maize evaluated by gene disruption of the trichodiene synthase (tri5) gene in three field isolates of different chemotype and virulence. Mol. Plant Pathol. 7:449-461.

24. Maragos, C., Busman, M., and Sugita-Konishi, Y. 2006. Production and characterization of a monoclonal antibody that cross-reacts with the mycotoxins nivalenol and 4-deoxynivalenol. Food Addit. Contam. 23:816-825.

25. McDonald, B. A., and Linde C. 2002. Pathogen population genetics, evolutionary potential, and durable resistance. Annu. Rev. Phytopathol. 40:349-379.

26. McMullen, M., Jones, R., and Gallenberg, D. 1997. Scab of wheat and barley: A re-emerging disease of devastating impact. Plant Dis. 81:13401348.

27. Miedaner, T., Cumagun, C. J. R., and Chakraborty, S. 2008. Population genetics of three important head blight pathogens Fusarium graminearum, F. pseudograminearum and F. culmorum. J. Phytopathol. 156:129-139.

28. Minervini, F., Fornelli, F., and Flynn, K. M. 2004. Toxicity and apoptosis induced by the mycotoxins nivalenol, deoxynivalenol and fumonisin B1 in a human erythroleukemia cell line. Toxicol. Vitro 18:21-28.

29. Mirocha, C. J., Abbas, H. K., Windels, C. E., and Xie, W. 1989. Variation in deoxynivalenol, 15-acetyldeoxynivalenol, 3-acetyldeoxynivalenol, and zearalenone production by Fusarium graminearum isolates. Appl. Environ. Microbiol. 55:1315-1316.

30. Mitter, V., Francl, L., Ali, S., Simpfendorfer, S., and Chakraborty, S. 2006. Ascosporic and conidial inoculum of Gibberella zeae play different roles in Fusarium head blight and crown rot of wheat in Australia and the USA. Australas. Plant Pathol. 35:441-452.

31. Nganje, W. E., Bangsund, D. A., Leistritz, F. L., Wilson, W. W., and Tiapo, N. M. 2004. Regional economic impacts of Fusarium head blight in wheat and barley. Rev. Agric. Econ. 26:332-347.

32. O’Donnell, K., Kistler, H. C., Tacke, B. K., and Casper, H. H. 2000. Gene genealogies reveal global phylogeographic structure and reproductive isolation among lineages of Fusarium graminearum, the fungus causing wheat scab. Proc. Natl. Acad. Sci. USA 97:7905-7910.

33. O’Donnell, K., Ward, T. J., Aberra, D., Kistler, H. C., Aoki, T., Orwig, N., Kimura, M., Bjørnstad, Å, and Klemsdal, S. S. 2008. Multilocus genotyping and molecular phylogenetics resolve a novel head blight pathogen within the Fusarium graminearum species complex from Ethiopia. Fungal Genet. Biol. 45:1514-1522.

34. O'Donnell, K., Ward, T. J., Geiser, D. M., Kistler, H. C., and Aoki, T. 2004. Genealogical concordance between the mating type locus and seven other nuclear genes supports formal recognition of nine phylogenetically distinct species within the Fusarium graminearum clade. Fungal Genet. Biol. 41:600-623.

35. Olsen, K. M. 1999. Minisatellite variation in a single-copy nuclear gene: Phylogenetic assessment of repeat length homoplasy and mutational mechanism. Mol. Biol. Evol. 16:1406-1409.

36. Pasquali, M., Giraud, F., Brochot, C., Cocco, E., Hoffman, L., and Bohn, T. 2009. Genetic Fusarium chemotyping as a useful tool for predicting nivalenol contamination in winter wheat. Intern. J. Food Microbiol. 137:246-253.

37. Placinta, C. M., D’Mello, J. P. F., and MacDonald, A. M. C. 1999. A review of worldwide contamination of cereal grains and animal feed with Fusarium mycotoxins. Anim. Feed Sci. Technol. 78:21-37.

38. Pritchard, J. K., Stephens, M., and Donnelly, P. 2000. Inference of population structure using multilocus genotype data. Genetics 155:945959.

39. Qualset, C. O., and Shands, H. L. 2005. Safeguarding the Future of U.S. Agriculture: The Need to Conserve Threatened Collections of Crop Diversity Worldwide. University of California, Division of Agriculture and Natural Resources, Genetic Resources Conservation Program, Davis.

40. Schothorst, R. C., and Van Egmond, H. P. 2004. Report from SCOOP task 3.2.10 "Collection of occurrence data of Fusarium toxins in food and assessment of dietary intake by the population of EU member states." Subtask: Trichothecenes. Toxicol. Lett. 153:133-143.

41. Starkey, D. E., Ward, T. J., Aoki, T., Gale, L. R., Kistler, H. C., Geiser, D. M., Suga, H., Tóth, J., Varga, J., and O’Donnell, K. 2007. Global molecular surveillance reveals novel Fusarium head blight species and trichothecene toxin diversity. Fungal Genet. Biol. 44:1191-1204.

42. Suga, H., Gale, L. R., and Kistler, H. C. 2004. Development of VNTR markers for two Fusarium graminearum clade species. Mol. Ecol. Notes $4: 468-470$

43. Suga, H., Karugia, G. W., Ward, T., Gale, L. R., Tomimura, K., Nakajima, T., Miyasaka, A., Koizumi, S., Kageyama, K., and Hyakumachi, M. 2008. Molecular characterization of the Fusarium graminearum species complex in Japan. Phytopathology 98:159-166.

44. Tanaka, T., Hasegawa, A., Yamamoto, S., Lee, U. S., Sugiura, Y., and Ueno, Y. 1988. Worldwide contamination of cereals by the Fusarium mycotoxins nivalenol, deoxynivalenol, and zearalenone. 1. Survey of 19 countries. J. Agric Food. Chem. 36:979-983.

45. Taylor, J. W., Jacobson, D. J., Kroken, S., Kasuga, T., Geiser, D. M., 
Hibbett, D. S., and Fisher, M. C. 2000. Phylogenetic species recognition and species concepts in fungi. Fungal Genet. Biol. 31:21-32.

46. Walker, S. L., Leath, S., Hagler, W. M., Jr., and Murphy, J. P. 2001. Variation among isolates of Fusarium graminearum associated with Fusarium head blight in North Carolina. Plant. Dis. 85:404-410.

47. Ward, T. J., Bielawski, J. P., Kistler, H. C., Sullivan, E., and O'Donnell, K. 2002. Ancestral polymorphism and adaptive evolution in the trichothecene mycotoxin gene cluster of phytopathogenic Fusarium. Proc. Natl. Acad. Sci. USA 99:9278-9283.

48. Ward, T. J., Clear, R., Rooney, A., O’Donnell, K., Gaba, D., Patrick, S., Starkey, D., and Geiser, D. M. 2008. An adaptive evolutionary shift in Fusarium head blight pathogen populations is driving the rapid spread of more toxigenic Fusarium graminearum in North America. Fungal Genet. Biol. 45:473-484.

49. Windels, C. E. 2000. Economic and social impacts of Fusarium head blight: Changing farms and rural communities in the northern Great Plains. Phytopathology 90:17-21.

50. Xu, X., and Nicholson, P. 2009. Community ecology of fungal pathogens causing wheat head blight. Annu. Rev. Phytopathol. 47:83-103.

51. Yang, L., van der Lee, T., Yang, X., Yu, D., and Waalwijk, C. 2008. Fusarium populations on Chinese barley show a dramatic gradient in mycotoxin profiles. Phytopathology 98:719-727.

52. Yli-Mattila, T., Gagkaeva, T., Ward, T. J., Aoki, T., Kistler, H. C., and O'Donnell, K. 2009. A novel Asian clade within the Fusarium graminearum species complex includes a newly discovered cereal head blight pathogen from the Far East of Russia. Mycologia 101:841-852.

53. Yoshizawa, T., Kohno, H., Ikeda, K., Shinoda, T., Yokohama, H., Morita, K., Kusada, O., and Kobayashi, Y. 2004. A practical method for measuring deoxynivalenol, nivalenol and T-2 + HT-2 toxin in food by an enzyme-linked immunoabsorbent assay using monoclonal antibodies. Biosci. Biotechnol. Biochem. 68:2076-2085.

54. Zeller, K. A., Bowden, R. L., and Leslie, J. F. 2004. Population differentiation and recombination in wheat scab populations of Gibberella zeae from the United States. Mol. Ecol. 13:563-571.

55. Zhang, D.-X., and Hewitt, G. M. 2003. Nuclear DNA analyses in genetic studies of populations: Practice, problems and prospects. Mol. Ecol. 12:563-584.

56. Zhang, J.-B., Li, H.-P., Dang, F.-J., Qu, B., Xu, Y.-B., and Zhao, C.-S., and Liao, Y. C. 2007. Determination of the trichothecene mycotoxin chemotypes and associated geographical distribution and phylogenetic species of the Fusarium graminearum clade from China. Mycol. Res. 111:967-975. 